DISCURSO 



\section{DISCURSO 6 DE ENERO 2015}

Dra. Elizabeth Bazán Gayoso rscj. ${ }^{1}$

Un saludo cariño, cercano, de hermana para cada uno de ustedes, con los que vengo compartiendo día a día esta preciosa misión de educar y un gracias porque son y los siento familia del Sagrado Corazón.

Gracias es la palabra justa y necesaria, para decirla muy de corazón a nuestra querida Hermana Elga García que por 20 años ha acompañado y contribuido a lo que es hoy UNIFÉ. Le agradecemos su cercanía y escucha a todos, su gran preocupación por la pastoral y la proyección social, la vivencia profunda del carisma de Santa Magdalena Sofía, que ha sabido contagiar, el impulso que ha dado a la universidad en fidelidad a sus principios fundacionales.

Al asumir el Rectorado lo hago con sencillez y fe, porque lo que logra UNIFÉ es conquista de toda la comunidad universitaria, de todo el cuerpo, con sus diversos carismas.

Hemos celebrado Bodas de Oro, nuestra historia está llena de presencias, nuestras Rectoras: Graciela Marrou, Gladys Buzzio, Luz María Alvarez Calderón, Raquel Corrales, Elga García, fieles a la inspiración educativa de Santa Magdalena Sofía Barat, nuestra fundadora, han sabido mantener viva la identidad atentas a la formación humana y profesional de la juventud, a las necesidades de las personas y a las demandas de la educación. Quedan las huellas del paso de muchos hermanos y hermanas nuestras que aquí dieron su vida y de muchas generaciones de jóvenes hoy ya profesionales y mujeres significativas en el país.

Nuestra universidad es un don de Dios recibido a través de las hermanas Carmen Cubero y Graciela Marrou, que en un gesto profético, en 1964, con coraje y esperanza la hicieron nacer. Mujeres de visión, de rigor académico, de fe, creyeron en el dinamismo de la "pequeña semilla" que se despliega abriéndose a la sociedad, comunicando vida, abriendo horizontes.

Nuestra comunidad universitaria atesora el trabajo, esfuerzo, sueños, alegrías, esperanzas, dones de muchas generaciones de mujeres y hombres que hicieron su historia y nosotros la continuamos atentos/as a la vida que crece, cambia, se enriquece, nos desafía, nos llama a la unidad, nos urge a recrear el gozo, el entusiasmo, la mística de los inicios.

Agradezco a todos/as ustedes, miembros de esta comunidad universitaria por el espíritu de familia, de alegría de servicio, de colaboración que aquí se vive, la gran sensibilidad social en nuestras estudiantes, el empeño que se pone en la formación integral de las profesionales de alta calidad ética y académica, el impulso que se da a la creatividad e innovación. La fuerza educativa de UNIFÉ que anima a todo el cuerpo comunica esperanzas.

Todos somos UNIFÉ, con la misma dignidad, todos somos importantes y queremos darnos oportunidades para continuar creciendo, desplegando nuestras potencialidades y ayudándonos a ser competentes en nuestro servicio educador desde la instancia en la que aportamos.

Como toda institución universitaria, UNIFÉ tiene sus principios, sus opciones: la búsqueda de la verdad, del sentido de la realidad, la afirmación de los valores cristianos, el servicio a la comunidad que nos exigen seguir trabajando la voluntad de investigar y el impulso a la investigación, la extensión

1 Religiosa del Sagrado Corazón. Bachiller y Licenciada en Humanidades. Doctora en Educación por la Universidad Femenina del Sagrado Corazón. Actualmente Rectora de la Universidad Femenina del Sagrado Corazón (UNIFÉ) 
universitaria, proyección social, la ciencia con conciencia, el trabajo interdisciplinario y multidisciplinario que nos abren al mundo en su complejidad.

Somos universidad, por lo tanto abiertas a lo universal. La variedad e intensidad de los desafíos del país y del mundo, y la importancia de las consecuencias de las decisiones que tomamos, nos pide trabajar el discernimiento; el proceso de interrelación creciente a nivel mundial, avanzar en aplicación de la tecnología; los modelos de crecimiento no centrados en la persona, que atentan contra el planeta y acentúan la vulnerabilidad de las personas, nos urgen a tener en cuenta las relaciones entre naturaleza, tecnología y ética, a colaborar en la "justicia climática" y afirmar la centralidad de la persona.

Zubiri nos recuerda que cuando una comunidad se enraíza en una realidad, se personaliza; enraizarnos significa en la práctica inclusión; un contexto multicultural como el nuestro es una riqueza y tenemos que afirmar el paso ético hacia la interculturalidad, conocer y sentir la realidad de nuestro país que tiene necesidades reales: tremenda desigualdad, fracturas éticas, violencia... Nos reconocemos parte de él con sus fortalezas y debilidades. Como profesionales tenemos que enriquecer las líneas de participación en la problemática. La formación en valores permanentes que se refuerza en esta universidad son: soporte de lo humano, valores del reino, y nos están exigiendo una respuesta desde donde nos toca trabajar, esto es construir sobre roca.

El Papa Francisco nos invita a vivir el presente con pasión, manteniéndonos en atenta escucha de lo que el Espíritu nos dice hoy a través de los signos de los tiempos y que en una sociedad del enfrentamiento, de la difícil convivencia entre culturas diferentes, del atropello contra los más débiles y de las desigualdades, estamos llamados a ofrecer un modelo concreto de comunidad.

Hago mías las palabras del Papa Francisco a los jóvenes que vale para todos nosotros: "No nos dejemos robar el deseo de construir con nuestras vidas cosas sólidas y grandes! ... aquello que nos lleva adelante. iNo nos demos por contentos con metas pequeñas! Aspiremos a la felicidad, tengamos la valentía, el coraje de salir de nosotros mismos, de jugarnos en plenitud el futuro junto con Jesús (Mensaje del Papa Francisco a los jóvenes (Río, Brasil 2013)

Nos recuerda que la Universidad ha sido, y está llamada a ser siempre, la casa donde se busca la verdad propia de la persona humana. No perdamos nunca la sensibilidad e ilusión por la verdad; ni olvidemos que a los jóvenes tenemos que comprender y querer, suscitar en ellos la sed de verdad que poseen en lo profundo y su afán de superación, seamos para ellos estímulo y fortaleza. "No podemos avanzar en el conocimiento de algo si no nos mueve el amor; ni tampoco amar algo en lo que no vemos racionalidad" (Discurso del Papa en su encuentro con profesores universitarios de Madrid. 2014)

Renovemos nuestra actitud de "abrazar el futuro con esperanza" en medio de las incertidumbres el futuro lo vamos haciendo nosotros, abriendo los ojos a nuevos horizontes, discerniendo, y juntos tomando las decisiones adecuadas y creativas. 